\title{
Monitoring Spatial and Seasonal Abundance of Indian Wild Ass (Equus hemionus khur) in Little Rann of Kutch Landscape, Western India
}

\author{
Bidyut B. Barman ${ }^{1 *}$, Nita Shah", Ashish Prasad', Abesh Sanyal², Vishal Chavda³ and Qamar Qureshi ${ }^{1}$ \\ 'Wildlife Institute of India, Chandrabani, Post Box No.18, Dehradun - 248001, Uttarakhand, India; bidyutb8@gmail.com \\ ${ }^{2} Z$ oological Survey of India, Dharamtala, Taltala, Kolkata-700016, West Bengal, India \\ 3Van Chetna Kendra, Vastrapur, Ahmedabad - 380015, Gujarat, India \\ ${ }^{4}$ Bombay Natural History Society, Hornbill House, Dr. Salim Ali Chawk, Shaheed Bhagat Singh Road, \\ Mumbai - 400001, Maharashtra, India
}

\begin{abstract}
The present study was conducted in Little Rann of Kutch (LRK) landscape in the Gujarat state of western India. It is a vast saline mud-plain holding the last remaining source population of Indian wild ass (Equus hemionus khur) or Khur after its population from other parts of the world got locally extinct. Khur occupy fringes of the Sanctuary and bets (islands) having grassland and scrubland vegetation. Taking adequate and effective management decisions and monitoring would be difficult in absence of reliable information. Line transect sampling will ensure robust population estimate of Khur. By bridging this gap with adequate information, meaningful and effective management decisions can be taken. We have conducted line transect surveys using foot and vehicle transect following distance sampling in southern fringe as intensive study site. The density estimates (No./km² $\pm \mathrm{SE}$ ) in southern fringe of LRK during two surveys were $5.76 \pm 0.91,6.08 \pm 1.39$ in winter and $2.29 \pm 0.55$ in summer from foot transect and $5.2 \pm 0.73,6.72 \pm 1.12$ in winter and $4.29 \pm 0.87$ in summer from vehicle transect, respectively. The study will help managers to evaluate long term monitoring method and make adaptive management decisions.
\end{abstract}

Keywords: Khur, Line Transect, Population Density, Semi-arid Landscape, Surra

\section{Introduction}

Population variability over time due to various factors has been the central goal of animal ecology ${ }^{1}$. To make decisions regarding conservation management, we need precise estimates of population density of the target species. Indian wild ass or Khur (Equus hemionus khur) population had been estimated using line transect sampling for the first time in LRK in 1998 by Gujarat Forest Department ${ }^{26}$ which was not exercised in following surveys. The global habitat of Khur that was once wide-spread in the Indian subcontinent across the western arid landscape of Pakistan, Baluchistan and Afghanistan is now restricted to the LRK landscape ${ }^{2-5,27}$ which is 5000 square kilometre of saline desert covered with brine and windblown sand. The landscape is the last remaining home of Khur which has been playing the role of an ecosystem specific to large herbivores by shaping the structure of the landscap ${ }^{6,30}$. Khur is a generalist grazer, which consumes large amount of roughage for their dietary need ${ }^{7,8}$. The high dependency on grassland communities makes them the landscape engineer crucial to conserve the Semi-arid ecosystem of LRK ${ }^{1,3}$, thus estimation of population density is important to conserve and manage their population and habitat ${ }^{9-11}$. Being one of the rare species, it has been kept under Schedule-I of the Wildlife Protection Act, 1972 and considered Near Threatened in IUCN Red List ${ }^{29}$. The Khur population was estimated to be 4000 in $1946^{12}$ which suffered sharp decline with an estimated population of 800 individuals during early 60's due to disease named "Surra (a parasitic disease caused by trypanosomes)" and consecutive severe droughts ${ }^{3,5,12,13}$. The ability to thrive in extremely human dominated landscape and protection measures taken up by declaring Wild Ass Sanctuary in 1972 revived the population to 3000 individuals in 1998 and since then a steady growth in population has been documented ${ }^{3,14}$. Also, in a Semi-arid ecosystem, population of large herbivore fluctuates due to its unpredictable weather change and change in forage quality

${ }^{*}$ Author for correspondence 
and quantity ${ }^{15}$. The impact of decreased forage density is much higher on desert ungulate than any other resource. The drought in a Semi-arid ecosystem could cause catastrophic decline in large ungulate populations ${ }^{16}$ with higher probability of zoonotic diseases getting transmitted from the livestock. Surra is still seen in this area and is affecting the population (Dr. Nita Shah press com). Apart from environmental and ecological stochasticities, the highly human dominated landscape with villages surrounding the protected area boundary exhibits direct or indirect dependencies on the Khur habitat where human added factors such as changing land use vary spatially and temporally that could impact decision making on habitat selection ${ }^{17}$. Therefore, it is important to know the population dynamics in order to understand their strategies on habitat selection and behavioural adaptations governing their movement across the landscape. Long term monitoring of population through temporally spaced population estimation of the same area for several decades or at same time surveying different sites could only give us the proper understanding of trends in spatial and temporal changes in their population density ${ }^{18,19}$. At the same time, abundance of sympatric herbivore including livestock which occur in the same foraging space is equally important. Abundance of livestock (cattle and buffalo) observed to higher in the southern fringe $\left(41.65 / \mathrm{km}^{2}\right.$ from foot transect in post-monsoon) during this study at the onset of monsoon season. Competition over shared space and diet is a density-dependent factor which could potentially govern the impact of livestock on Khur population dynamics ${ }^{28}$. Considering all the challenges associated to the landscape, long term Khur population management needs regular monitoring and adequate information. In this study, we monitored Khur population density using line transect method $^{20}$ to generate population estimates and bridge the knowledge gap to help management to assimilate effective conservation strategies.

\section{Materials and Methods}

\subsection{Study Area}

The semi-arid landscape including the saline mud-plain and surrounding fringe villages are together called LRK landscape which is about $5000 \mathrm{~km}^{2}$ area and is located within $23^{\circ} 10^{\prime}$ $23^{\circ} 45^{\prime}$ north and $70^{\circ} 45^{\prime}-71^{\circ} 45^{\prime}$ east. Total $4953.71 \mathrm{~km}^{2}$ area of LRK landscape was notified as the Indian Wild Ass Sanctuary. The landscape is just above the sea level adjoining the Gulf of Kutch of Gujarat state. The major vegetation is dominated by Prosopis juliflora scrub. Among native tree species Acacia nilotica, A. senegal, Salvadora persica, S. oleoides are present in sporadic patches along the fringe. The LRK comprises of three distinct surface features: 1 . Rann (the exposed saline mud- flats in which almost nothing grows), 2. The higher islands or sandy soils, nearly free from salt with a cover of grass and sparse scrubs, commonly called 'bets' or 'islands' and 3. The shore or fringes of the mainland which border the Rann and support scattered vegetation. About 75 islands (bets) with vegetation growth of which, 10 are major bets that used as breeding ground by Khur in monsoon. In monsoon, the entire sanctuary gets inundated by rain water and become a wetland for 2 to 3 months which is the peak breeding season of Khur.

\subsection{Method}

The line transect sampling was done to survey the LRK landscape. In this study, southern fringe was selected as the intensive study area to monitor change in population density over the period of 3 years from 2012-13 to 2015-16. Line transect sampling was performed by foot and vehicle transect method. In 2012-13 and 2015-16, during winter season, the southern fringe was surveyed using foot transect method. Similarly, vehicle transect was sampled in 2014 and 2015 during winter season. During summer season, in 2014, the southern fringe was surveyed using both foot and vehicle transect method.

In foot transect sampling, the fringe areas were walked whereas in vehicle transect, along with the fringe areas, the larger saline-plain adjacent to the southern fringe was surveyed. Foot transects were laid over the village trails that start from village and end into the Rann. These trails were sampled following systematic random sampling design where starting points were randomly selected ${ }^{26}$. On each observation, the cluster size, sighting angle, radial distance, habitat type and geographical location were recorded.

\subsection{Data Analysis}

The data was analysed using DISTANCE 7.3 software in Conventional Distance Sampling (CDS) module ${ }^{20}$.

\section{Results}

\subsection{Density of Khur in Southern Fringe (Intensive Area)}

In winter seasons of 2012-13 and 2015-16, density estimates $\left(\mathrm{No} . / \mathrm{km}^{2}\right)$ from foot transects were $5.76 \pm 0.95$ and $6.08 \pm$ 1.39 with walk efforts of $154.49 \mathrm{~km}$ and $75.53 \mathrm{~km}$, respectively (Table 1). From vehicle transect samplings in winter seasons of 2014 and 2015, density estimates were $5.2 \pm 0.73$ and $6.72 \pm$ 1.12 with total efforts $111 \mathrm{~km}$ and $93.89 \mathrm{~km}$, respectively (Table 2). Mean cluster sizes were $5.15 \pm 0.54,4.9 \pm 0.63,4.05 \pm 0.46$ and $6.3 \pm 0.65$ in winter surveys by foot and vehicle transect, 


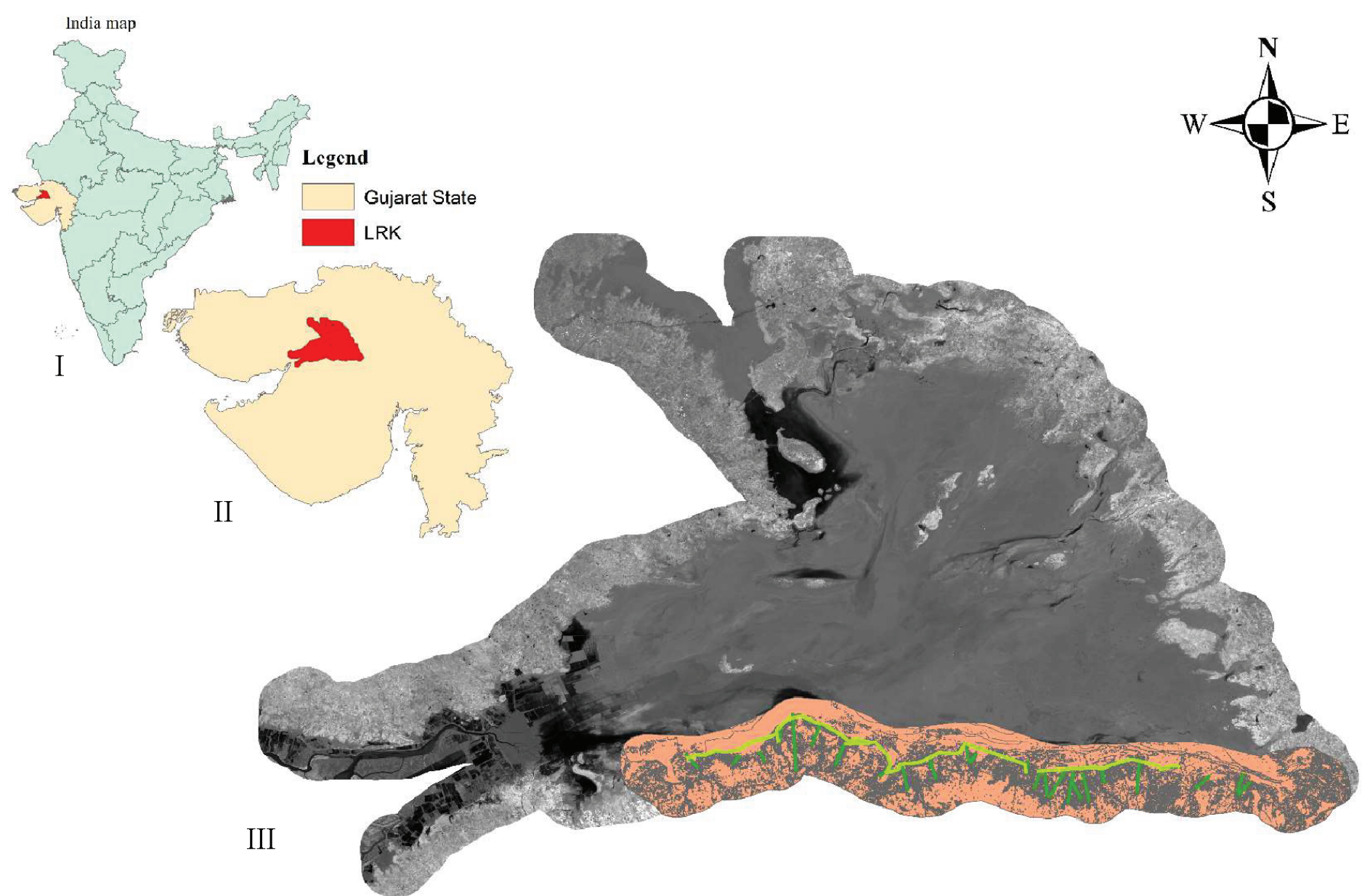

Southern Fringe of LRK

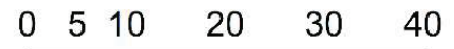

Kilometers

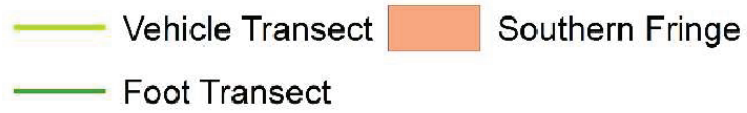

Figure 1. I. Recent political map of India with all states, II. State of Gujarat and Little Rann of Kutch landscape, III. LRK landscape and southern fringe area (intensive study site) with foot and vehicle transect samples.

Table 1. Population estimates from Conventional Distance Sampling of southern fringe during winter and summer seasons from foot transect

\begin{tabular}{|c|c|c|c|c|c|c|}
\hline \multirow[t]{2}{*}{ Parameters } & \multicolumn{2}{|c|}{ 2012-13 (Winter) } & \multicolumn{2}{|c|}{ 2015-16 (Winter) } & \multicolumn{2}{|c|}{2014 (Summer) } \\
\hline & Estimate & $\% \mathrm{CV}$ & Estimate & $\% \mathrm{CV}$ & Estimate & $\% \mathrm{CV}$ \\
\hline Sample & 44.00 & & 23.00 & & 28.00 & \\
\hline Effort & 170.95 & & 79.73 & & 100.76 & \\
\hline Observations & 167.00 & & 78.00 & & 56.00 & \\
\hline ESW & $362.88 \pm 9.93$ & 2.74 & $362.88 \pm 9.93$ & 2.74 & $362.88 \pm 9.93$ & 2.74 \\
\hline Density of cluster & $1.35 \pm 0.16$ & 12.26 & $1.35 \pm 0.25$ & 18.48 & $0.77 \pm 0.16$ & 20.57 \\
\hline Mean cluster size & $5.15 \pm 0.54$ & & $4.9 \pm 0.63$ & & $3.39 \pm 0.35$ & \\
\hline $\begin{array}{l}\text { Density (No./ } \\
\mathrm{km}^{2} \text { ) }\end{array}$ & $5.76 \pm 0.91$ & 15.93 & $6.08 \pm 1.39$ & 22.99 & $2.29 \pm 0.55$ & 24.07 \\
\hline Encounter rate & 0.98 & 11.95 & 0.98 & 18.28 & 0.56 & 20.39 \\
\hline
\end{tabular}


Table 2. Population estimates from Conventional Distance Sampling of southern fringe during winter and summer seasons from vehicle transect

\begin{tabular}{|c|c|c|c|c|c|c|}
\hline \multirow[t]{2}{*}{ Parameters } & \multicolumn{2}{|c|}{2014 (Winter) } & \multicolumn{2}{|c|}{2015 (Winter) } & \multicolumn{2}{|c|}{2014 (Summer) } \\
\hline & Estimate & $\% \mathrm{CV}$ & Estimate & $\% \mathrm{CV}$ & Estimate & $\% \mathrm{CV}$ \\
\hline Sample & 3.00 & & & & 17.00 & \\
\hline Effort & 111.00 & & & & 168.20 & \\
\hline Observations & 133.00 & & & & 93.00 & \\
\hline ESW & $399.99 \pm 10.4$ & 2.60 & $399.99 \pm 10.4$ & 2.6 & $313.13 \pm 24.47$ & 7.82 \\
\hline Density of cluster & $1.49 \pm 0.15$ & 10.26 & 1.10 .13 & 11.61 & $0.88 \pm 0.15$ & 17.04 \\
\hline Mean cluster size & $4.05 \pm 0.46$ & & $6.3 \pm 0.65$ & & $4.86 \pm 0.54$ & \\
\hline $\begin{array}{l}\text { Density } \\
\left(\mathrm{No} . / \mathrm{km}^{2}\right)\end{array}$ & $5.2 \pm 0.73$ & 14.08 & $6.72 \pm 1.12$ & 16.65 & $4.29 \pm 0.87$ & 20.29 \\
\hline Encounter rate & 1.19 & 9.93 & 0.88 & 11.32 & 0.55 & 15.14 \\
\hline
\end{tabular}

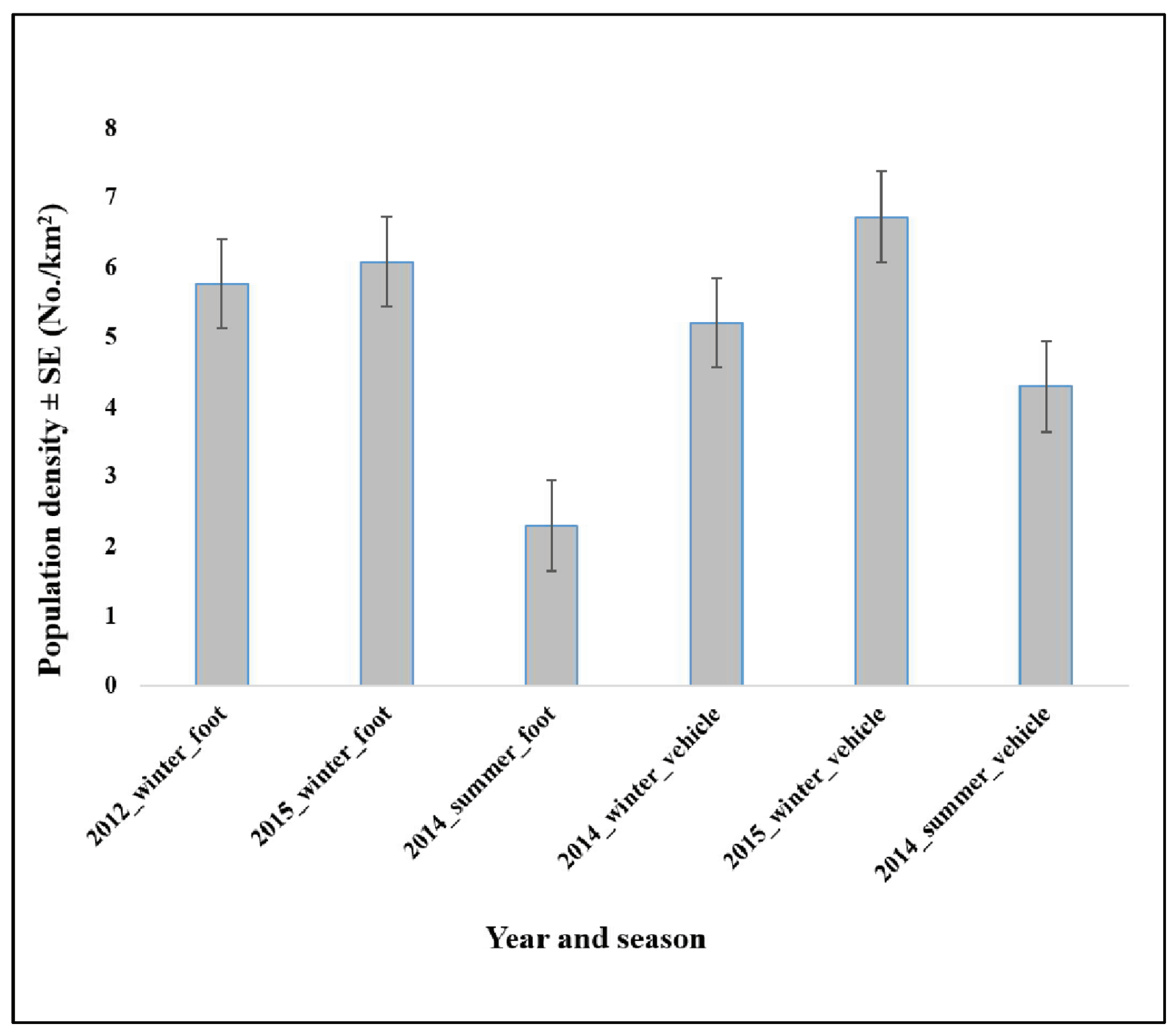

Figure 2. Bar-plot showing Khur population density in southern fringe during winter and summer season from foot and vehicle transect in different years. 


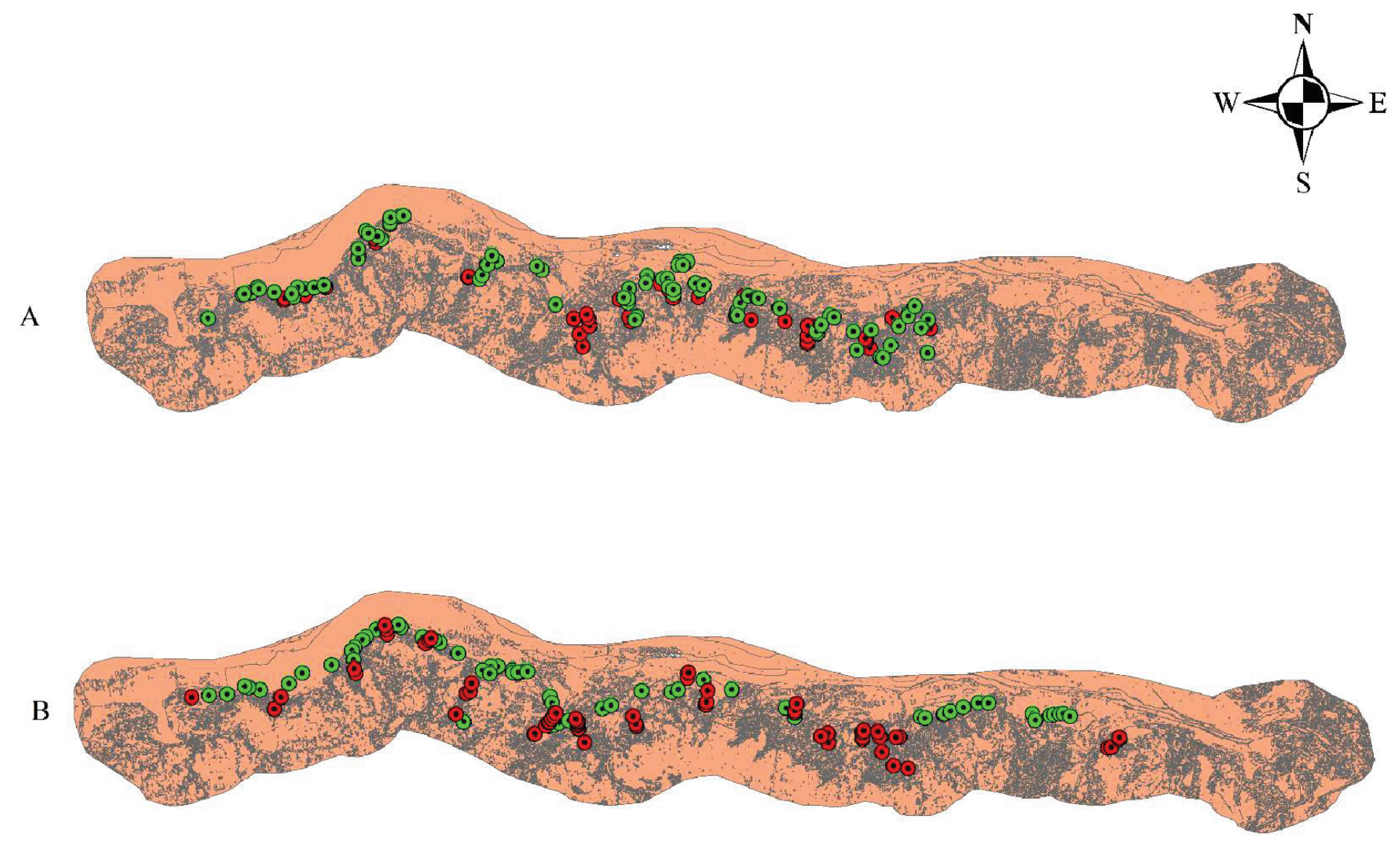

Southern Fringe of LRK
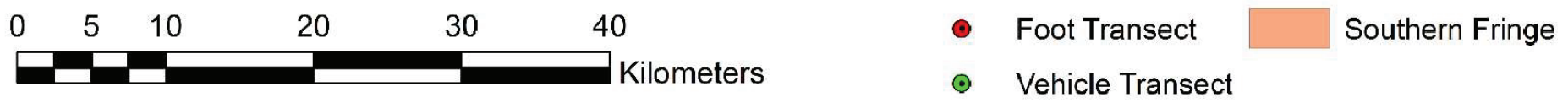

Figure 3. Distribution of Khur in southern fringe from foot and vehicle transect during; A. Summer season and B. Winter season.

respectively. In summer season in 2014, density of Khur was estimated at $2.29 \pm 0.55$ and $4.29 \pm 0.87$ with foot and vehicle transect samplings, respectively. The mean cluster sizes were $3.39 \pm 0.35$ and $4.86 \pm 0.54$, respectively in summer.

\section{Discussion}

Indian wild ass is a large ungulate and uniformly distributed along the fringe areas of Little Rann of $\mathrm{Kutch}^{3}$. The extensive use of trails and fringe habitats by the people has made the wild ass herds habituated towards human presence ${ }^{26}$. In Little Rann of Kutch, the prime wild ass habitats are the scrubland, grasslands with low or medium scrub growth, fallow-land and Rann. The thorny scrub-lands were difficult to penetrate in many parts and surface area is flat, so the trails were selected as transects following the basic assumptions of Distance sampling method ${ }^{20-22}$. The hoof makes the tapping sound like horses while running which was easily recognizable and was helpful in detecting their presence near the transect when they remain invisible due to the scrub thickets.

The southern and eastern fringe was the richest in terms of resource productivity where Khur groups were closely packed due to resource availability whereas the western and northern fringes were resource poor ${ }^{5}$. The population density did not change in winter surveys whereas in summer season, it was low. The mean cluster size was same in both the winter surveys and no remarkable change was observed in summer. It was assumed that the resource availability has an important density-dependent effect on Khur population by regulating their movements where although the adults remain less affected but infant survival and decreased fecundity rate might affect the population density as a whole ${ }^{23}$.

Khur breeds during monsoon season along the fringe and bet areas where grassland habitats remain highly productive ${ }^{3}$. 
Due to resource availability in terms of food and water, Khur herds show higher congregation with closely packed groups ${ }^{5}$. The herds with new born foals prefer fringe habitat due to good forage quality and lesser human movement in sanctuary area in monsoon. However, livestock population from the fringe villages graze in fringe habitats due to which fringe grassland habitats start degrading in forage quality and natural water sources also completely dried up towards the beginning of summer season. In summer, Khur groups tend to move outside sanctuary towards agriculture areas where food and water from irrigated farmlands are available and Khur density inside sanctuary decreases. After the development in Narmada canal irrigation system, entire southern fringe witnessed drastic change in terms of land use where majority of non-irrigated croplands and wastelands were converted into irrigated farmlands ${ }^{24}$ and the process was ongoing during the study. Reduced density in summer indicates the effect of change in resource availability in southern fringe. Studies suggested that individuals change their movement behaviour to adjust with the local habitat and show preference for some habitat types over others ${ }^{25}$. Also large herbivores are comparatively difficult to conserve in a human dominated landscape because of their unique tendency towards suitable habitat and crop raiding ${ }^{13}$. Due to large area of the landscape and harsh climatic conditions, population estimation at an interval of 5 years should continue. However, the total count does not indicate valuable insights into the population density across the landscape and in specific areas with rich occurrence. Following the study conducted by Shah and Qureshi (2007), present study observed similar distribution pattern of Khur along the southern fringe. Therefore, it is advisable to monitor the population in both winter and summer and associated density-dependent factors like new recruitment, mortality, habitat quality, water distribution and disease.

The study provides reliable population estimates of Khur from both foot and vehicle transect methods. During winter and summer, the saline plain remains accessible and vehicle transects can be convenient to exercise continuous monitoring with lesser man-power and within short period of times ${ }^{3,26}$. The regular census conducted by forest department at every 5 years interval should be done every 3 years using line transect sampling which would be economically viable in comparison to the exercise involving large man-power and possible to achieve reliable estimates of population density by checking biases involved in total count. Also, long term monitoring data would help in detecting and understanding change in population density. Further studies to understand the role of land use change and other human aided pressure on the habitat would help the management to take necessary steps in conserving the landscape and Khur population.

\section{Acknowledgement}

We sincerely thank the Gujarat Forest Department, officials and other forest staff of Wild Ass Sanctuary for providing all the necessary support to conduct the survey. We express our sincere gratitude to Director and Dean, WII for facilitating the implementation of the Grant-in-Aid project. We are grateful to WWF-India 'Flamingo Project' for funding towards the completion of the project. We sincerely thank Savjibhai, Chhaganbhai and their families for their assistance and support throughout the field work. We would like to thank the people of fringe villages in LRK landscape for their warm hospitality and support during the field work.

\section{Statements}

\section{Statements about Contributorship}

All the authors have contributed in the study.

Study design: Qamar Qureshi and Nita Shah

Data collection- B.B.Barman, Ashish Prasad, Abesh Sanyal and Vishal Chavda.

Data analysis and Manuscript writing: B.B.Barman

The final draft of manuscript was edited and approved by all authors.

\section{Statements for Competing Interest}

There is no competing interests among the authors.

\section{Statement for Data Sharing}

Manuscript contains all relevant data.

\section{Statement of Ethical Approval}

This study was conducted with the approval from Gujarat Forest Department and all guidelines and rules were followed.

\section{Reference}

1. Robinson JG, Redford KH. Body size, diet and population density of Neotropical forest mammals. The American Naturalist. 1986; 128(5):665-80. https://doi.org/10.1086/284596

2. Duncan P. Zebras, Asses and Horses: An action plan for the conservation of wild equids. IUCN:Gland, Switzerland; 1992. p. 36.

3. Shah NV. Ecology of wild ass (Equus hemionus khur) in Little Rann of Kutch. [Ph.D.Diss]. M.S. University, Baroda, Gujarat. 1993.

4. Moehlman PD. Equids--zebras, asses and horses: Status survey and conservation action plan. IUCN. 2000.

5. Shah N, Qureshi Q. Social organization and determinants of spatial distribution of Khur (Equus hemionus khur). Exploration 
into the Biological Resources of Mongolia. Erforsch Biol Ress. Mongolei (Halle/Saale). 2007; 10:189-200.

6. Ripple WJ, Newsome TM, Wolf C, Dirzo R, Everatt KT, Galetti M, Hayward MW, Kerley GI, Levi T, Lindsey PA, Macdonald DW. Collapse of the world's largest herbivores. Science Advances. 2015; 1(4):1400103. PMid: 26601172 PMCid: PMC4640652. https://doi.org/10.1126/sciadv.1400103

7. Schulz E, Kaiser TM. Historical distribution, habitat requirements and feeding ecology of the genus E quus (Perissodactyla). Mammal Review. 2013 Apr; 43(2):111-23. https://doi. org/10.1111/j.1365-2907.2012.00210.x

8. Ahrestani FS, Heitkonig IM, Matsubayashi H, Prins H.H. Grazing and browsing by large herbivores in South and Southeast Asia. In The Ecology of Large Herbivores in South and Southeast Asia. Springer, Dordrecht. 2016. p. 99-120. https://doi. org/10.1007/978-94-017-7570-0_4

9. Crawley, MJ. Herbivory: The dynamics of animal-plant interactions. Blackwell: Osney Mead, Oxford;1983.

10. Kortland A. Vegetation research and the "bulldozer" herbivores in tropical Africa. Sutton, S., Whitmore T.C. and 252. 1984. p. 205-26.

11. Karanth KU, Sinquist ME. Population structure, density and biomass of large herbivores in tropical forests of Nagarhole of India. Journal of Tropical Ecology. 1992; 8:21-35. https://doi. org/10.1017/S0266467400006040

12. Ali S. The wild ass of Kutch. J Bombay Nat Hist Soc. 1946; 46:472-7.

13. Gee EP. The Indian wild ass: A survey. J Bombay Nat Hist Soc 1963; 60:517-29.

14. Singh HS. Status of Indian wild ass (Equus hemionus khur) in the Little Rann of Kutch. Zoos Print Journal. 2000 May; 5:253-6. https://doi.org/10.11609/JoTT.ZPJ.15.5.253-6

15. Caughley G, Gunn A. Dynamics of large herbivores in deserts: Kangaroos and caribou. Oikos. 1993 May 1: 47-55. https://doi. org/10.2307/3545094

16. Illius AW, O'Connor TG. Resource heterogeneity and ungulate population dynamics. Oikos. 2000; 89:283-94. https://doi. org/10.1034/j.1600-0706.2000.890209.x

17. Krishna YC, Kumar A, Isvaran K. Wild ungulate decision - Making and the role of tiny refuges in human-dominated landscapes. PloS one. 2016 Mar 17; 11(3). PMid: 26985668 PMCid: PMC4795686. https://doi.org/10.1371/journal.pone.0151748

18. Droege S. The North American Breeding Bird Survey. Pages 1-4 in JR Sauer and S Droege, (eds.) Survey designs and statistical methods for the estimation of avian population trends. U.S. Fish Wildlife Service Biology Report. 1990; 90(1).
19. Pollock KH, Nichols JD, Simons TR, Farnsworth GL, Bailey LL, Sauer JR. Large scale wildlife monitoring studies: statistical methods for design and analysis. Environmetrics: The Official Journal of the International Environmetrics Society. 2002 Mar; 13(2):105-19. https://doi.org/10.1002/env.514

20. Buckland ST, Anderson AR, Burnham KP, Laake JL. Distance sampling: Estimating abundance of biological populations. Champion and Hall, London. 1993. p. 446. PMCid: PMC1676856. https://doi.org/10.1007/978-94-011-1574-2

21. Fewster RM, Southwell C, Borchers DL, Buckland ST, Pople AR. The influence of animal mobility on the assumption of uniform distances in aerial line-transect surveys. Wildlife Research. 2008 Jun 27; 35(4):275-88. https://doi.org/10.1071/WR07077

22. Melville GJ, Tracey JP, Fleming PJ, Lukins BS. Aerial surveys of multiple species: Critical assumptions and sources of bias in distance and mark-recapture estimators. Wildlife Research. 2008 Jun 27; 35(4):310-48. https://doi.org/10.1071/WR07080

23. Skogland T. The effects of density-dependent resource limitations on the demography of wild reindeer. The Journal of Animal Ecology. 1985 Jun 1: 359-74. https://doi.org/10.2307/4484

24. Goyal SP, Sinha B, Shah N, Panwar HS. Sardar Sarovar Project - a conservation threat to the Indian wild ass (Equus hemionus khur). Biological Conservation. 1999; 88(2):277-84. https://doi. org/10.1016/S0006-3207(98)00082-2

25. Zaker N, Ketchemen L, Lutscher F. The effect of movement behavior on population density in patchy landscapes. Bulletin of Mathematical Biology. 2020; 82(1):1-24. PMid: 31919597. https://doi.org/10.1007/s11538-019-00680-3

26. Shah N. Wild ass. Singh, HS, Patel, BH, Parvez R, Soni VC, Shah NV, Tatu K, Patel D. (eds.): Ecological study of wild ass sanctuary little rann of kutch. 1999.

27. Mahar N, Mungi NA, Sutirtha L. Beyond nationality: Opportunity for trans-boundary wildlife conservation. DIALOGUE: Science, Scientists and Society. 2021; 4. https://doi.org/10.29195/ DSSS.03.01.0029

28. Prins HH. Competition between wildlife and livestock in Africa. In Wildlife conservation by sustainable use. Springer, Dordrecht. 2000. p. 51-80. https://doi.org/10.1007/978-94-011-4012-6_5

29. Kaczensky P, Lkhagvasuren B, Pereladova O, Hemami M, Bouskila A. Equus hemionus ssp. khur. The IUCN Red List of Threatened Species. 2016. https://dx.doi.org/10.2305/IUCN. UK.2016-.RLTS.T7963A3144616.en

30. Johnsingh AJ, Manjrekar N. Mammals of South Asia, Volume II. University Press (India) Private Limited. 2015, Chapter 39, pp. 112-128. 